\title{
Factors affecting crop diversification on tribal farming: A case study from Eastern ghats of India
}

\author{
Sadasiba Tripathy*and Dr. Sandhyarani Das \\ Berhampur University, Berhampur-760007, Odisha, India
}

\begin{abstract}
In this article we investigated various factors affecting crop diversification in tribal areas of Eastern ghats of India. We adopted multiple regression analysis and tried to visualize contribution from different factors to crop diversification. We observe most prominent factor affecting to tribal farming in study area is fertilizers, while least one is irrigation facility. Few policy suggestions are made for their betterment based on this study.
\end{abstract}

Key words - Diversification of agriculture, Tribal farming, Farm households JEL codes- Q10, Q12, Q13

\section{Introduction}

\subsection{Introduction to tribal farming}

Agriculture, forest collection, hunting practices are the prime characteristics of tribal livelihood. They spent much of their time in their agricultural fields and worship the land as the mother goddess. Shift cultivation (Podu cultivation) was used to be a beneficial practice in tribal farming where they used to grow millets. They used the organic farming for their agricultural practices up to 2003-04 but now a days they are adopting the use of chemical fertilizers and modern techniques to raise the agricultural productivity and income. In the last 2 decades the tribal farming undergone a big change so it is important to study this from the development perspective

Crop diversification is one of those steps which raise the per capita income of the farmers [5]. So it is very much important to study the factors that effect the crop diversification. Because of their diversified practice they are now getting accustomed with the needs of the modern agricultural requirements. Although a larger sectio of them still follow traditional methods. For example, Rainfall is a prime need for the paddy and millets. Those were on shift cultivation, off time rainfall makes the loss for a whole year, while on land based agriculture off-time pushes harvesting almost to zero. So along with impact of diversification, it is essential to investigate factors which might affect the diversification.

Eastern ghats of India, have tribal dominated areas, even few of primitive tribal groups are used to live here for generations. The study attracts our concentration to the 5 tribal dominated villages of Koraput district $\left(18.8135^{\circ} \mathrm{N}, 82.7123^{\circ} \mathrm{E}\right)$ where more than $60 \%$ of the inhabitants are tribals (Raniput/Village 1, Soralguda/Village2, Mundaguda/Village 3, Ekomba/Village 4 and Rupabeda/Village 5) We have taken purposive sampling to choose the tribal dominated villages. Authors collected primary data of $80 \%$ of sample households, on the basis of simple

\footnotetext{
*tripathy.sadasiba@gmail.com
} 
random sampling. A questionnaire was developed to collect the data and to know the present agricultural practice and the impact of the factors responsible for crop diversification in the study area.

Objective of this study is to figure out the crucial factors affecting tribal famers practices in study area. And as a result from this investigation, to recommend policy suggestions to develop better practices so as to increase the standard of living of tribal farmers in the study area.

\subsection{Profile of the Study Area}

The selected villages are tribal dominated villages, and as per the figure the tribal concentration is more than $60 \%$. As per table-1 the households of the sample villages vary from 68 to 132 [1]. The total population of each of the sample villages is from 227 to 608 numbered. If we would compare the rate of literacy of the sample villages ranges from $16 \%$ to $53.91 \%$ and average of state is $72.87 \%[1]$.

Table 1: Population as per 2011 census $[1,5]$

\begin{tabular}{l|l|l|l|l|l}
\hline Particulars & Village 1 & Village 2 & Village 3 & Village 4 & Village 5 \\
\hline No. of families & 103 & 122 & 134 & 100 & 68 \\
\hline Total family members & 495 & 423 & 608 & 442 & 227 \\
\hline Child (0-6 age) & 108 & 84 & 130 & 71 & 41 \\
\hline Schedule Tribe (in \%) & 65.05 & 64.77 & 77.3 & 80.77 & 99.56 \\
\hline Schedule Caste (in \%) & 20.08 & 21.04 & 0. & 0.97 & 0. \\
\hline Literacy (in \%) & 38.76 & 36.58 & 35.36 & 53.91 & 16.13 \\
\hline
\end{tabular}

The working sectors are the real contributors in these sample villages. The main workers, those who get work more than 6 months, are from 144 to 317 numbered. And the people who get the work less than 6 months are from are called marginal workers [1]. They are ranged from $43.06 \%$ to $64.79 \%$.

Table 2: Work profile as per 2011 census $[1,5]$

\begin{tabular}{c|c|c|c|c|c}
\hline Particulars & Village 1 & Village 2 & Village 3 & Village 4 & Village 5 \\
\hline Total Workers & 215 & 244 & 317 & 267 & 144 \\
\hline Main Worker (in \%) & 45.12 & 47.95 & 47 & 35.12 & 56.94 \\
\hline Marginal Worker (in \%) & 54.88 & 52.05 & 53 & 64.79 & 43.06 \\
\hline
\end{tabular}

\subsection{Factors affecting crop diversification}

The factors like Rainfall, Fertilizers, Land type, Availability of market, Farmers Knowledge, cold store house, HYV seeds; and Irrigated area are few observed factor responsible for crop diversification in the study area [8].

Rainfall:

Rainfall can be productive or un-productive [8]. If it rains in time then it yields a lot and vis-a vis. Here we have taken the irrigated villages and if the rain becomes unproductive i.e. due to the water concentration at roots will destroy the plants and the process of diversification disturbs. So the natural factors like rain have an impact of the crop diversification.

Fertilizers:

Another important factor is the use of fertilizer [8]. Farmers use different types of fertilizers for different purposes. They use POTAS for the growth in the size of the fruits and DAP for the growth of the plants and URIA to maintain a good soil health. Again they view that use of 
bio-fertilizer (cow-dung manure) is better than the chemical fertilizer but due to less availability of the bio-fertilizer, they are somehow compelled to use the chemical fertilizer in their fields.

Land type:

Another important variable is land type [8]. The practice of vegetable production can be better in case of upland and medium land. In low land there will be concentration of water and will lead to vegetable crops loss. In low land, there are maximum instances of crop concentration viz. traditional crops like paddy. Rather than crop diversification that will lead to crop concentration.

Availability of market:

The availability of nearby markets will be helpful for the farmers for easy transportation and a good supporting price even to the unsold vegetables for the next day. There is a also a different concept of market i.e. weekly market and in this market people come from different places surrounded to the villages and the farmers have an opportunity to sell the products at a higher volume than in from regular markets. Mandi is also a traditional system and is meant for selling of both paddy and vegetables. In tribal areas the concept of Mandi is popular for the selling of Paddy.

Farmers Knowledge:

The department of horticulture provides the training to the farmers for vegetable cultivation and also pays some remuneration for this training. If they will attend the training program, they will get Rs. 1000 per day or Rs. 5000 per day per farmer within and outside of the state respectively. A part from this they visit the to the villages and talk to the S.H.G.s and train them with the cultivation techniques, So farmers knowledge plays an important role in diversifying the crop.

Cold store house:

Storage facility is the prime requisite in the way of crop diversification. As there is no such storage facility in close vicinity of village and after 3 to 4 days [9], they are bound to sell it in a lesser price.

HYV seeds:

High Yield Variety (HYV) seeds are the seeds that has been developed in order to have a better production sometimes it gives 7 times more [8]. The father of green revolution Ms Swaminathan has developed the seed for the promotion of green revolution and to get the sustainable development [10]

Irrigation:

Irrigation is one of the important factors of crop diversification in that region [8]. They have Lift Irrigation facilities pump sets, hand pumps and dug-well which they use for this purpose. So they can use the water according to their need and requirement. Initially they make the lines of knurl and after that they use the water.

\section{Model}

We measured impact of different factors on crop diversification, through Multiple Linear Regression (MLR) model. Here we have taken crop diversification as the independent variable and different factors as dependent variable. MLR may be written as [4]:

$$
\mathrm{Y}=\mathrm{b}_{0}+\sum_{\mathrm{i}} \mathrm{b}_{\mathrm{i}} \mathrm{X}_{\mathrm{i}}+\varepsilon
$$

Where, $\mathrm{Y}=$ dependent or predicted variable (here CDI),

$\mathrm{X}_{\mathrm{i}}=$ independent or explanatory variable,

$\mathrm{b}_{0}=\mathrm{y}$-intercept (constant term),

$b_{i}=$ regression coefficients or slope coefficient for each explanatory variable,

and $\varepsilon$ is error term or residual. 
Table 3: Factors affecting crop diversification [12]

\begin{tabular}{|c|c|c|c|c|c|c|}
\hline Year & Factors & Village 1 & Village 2 & $\begin{array}{l}\text { Village } \\
3\end{array}$ & Village 4 & Village 5 \\
\hline \multirow[t]{9}{*}{ 2008-09 } & $\begin{array}{l}\text { Rainfall (per } \\
\text { month } / \mathrm{mm})[7]\end{array}$ & 215.03 & 74.1 & 92.88 & 147.172 & 139.2 \\
\hline & Fertilizers (Kg) & 165 & 250 & 275 & 150 & 100 \\
\hline & Irrigated area (in \%) & 36.4 & 6.56 & 16.39 & 23.23 & 0 \\
\hline & Land type & Medium & Medium & Medium & Medium & Upland \\
\hline & Farmers knowledge & $\begin{array}{l}\text { Un- } \\
\text { trained }\end{array}$ & $\begin{array}{l}\text { Un- } \\
\text { trained }\end{array}$ & Trained & $\begin{array}{l}\text { Un- } \\
\text { trained }\end{array}$ & $\begin{array}{l}\text { Un- } \\
\text { trained }\end{array}$ \\
\hline & $\begin{array}{l}\text { Availability of market } \\
(\mathrm{Km})\end{array}$ & 10.6 & 7 & 13 & 14.3 & 34.3 \\
\hline & Cold-store house & No & No & No No & No & No \\
\hline & HYV seeds & Yes & Yes & Yes & Yes & No \\
\hline & CDI [5] & 0 & 0.54 & 0.53 & 0.35 & 0 \\
\hline \multirow[t]{9}{*}{ 2013-14 } & $\begin{array}{l}\text { Rainfall (per } \\
\text { month/mm) [7] }\end{array}$ & 148.225 & 155.967 & 188.70833 & 257.125 & 181.75 \\
\hline & Fertilizers (Kg) & 200 & 250 & 275 & 150 & 150 \\
\hline & Irrigated area (in \%) & 52 & 14.66 & 21.11 & 27.92 & 8.72 \\
\hline & Land type & Medium & Medium & Medium & Medium & Upland \\
\hline & Farmers knowledge & $\begin{array}{l}\text { Un- } \\
\text { trained }\end{array}$ & $\begin{array}{l}\text { Un- } \\
\text { trained }\end{array}$ & Trained & $\begin{array}{l}\text { Un- } \\
\text { trained }\end{array}$ & $\begin{array}{l}\text { Un- } \\
\text { trained }\end{array}$ \\
\hline & $\begin{array}{l}\text { Availability of market } \\
(\mathrm{Km})\end{array}$ & 10.6 & 7 & 13 & 14.3 & 34.3 \\
\hline & Cold-store house & No & No & No No & No & No \\
\hline & HYV seeds & Yes & Yes & Yes & Yes & No \\
\hline & CDI [5] & 0.18 & 0.37 & 0.22 & 0.31 & 1. \\
\hline \multirow[t]{9}{*}{$\begin{array}{l}20018- \\
19\end{array}$} & $\begin{array}{l}\text { Rainfall (per } \\
\text { month } / \mathrm{mm} \text { ) [7] }\end{array}$ & 169.042 & $\overline{127.117}$ & 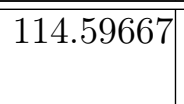 & 174.875 & 19193.85833 \\
\hline & Fertilizers $(\mathrm{Kg})$ & 220 & 300 & 275 & 220 & 180 \\
\hline & Irrigated area (in \%) & 57 & 26.23 & 59.84 & 36.6 & 17.15 \\
\hline & Land type & Medium & Medium & Medium & Medium & Upland \\
\hline & Farmers knowledge & $\begin{array}{l}\text { Un- } \\
\text { trained }\end{array}$ & $\begin{array}{l}\text { Un- } \\
\text { trained }\end{array}$ & Trained & $\begin{array}{l}\text { Un- } \\
\text { trained }\end{array}$ & $\begin{array}{l}\text { Un- } \\
\text { trained }\end{array}$ \\
\hline & $\begin{array}{l}\text { Availability of market } \\
(\mathrm{Km})\end{array}$ & 10.6 & 7 & 13 & 14.3 & 34.3 \\
\hline & Cold-store house & No & No & No No & No & No \\
\hline & HYV seeds & Yes & Yes & Yes & Yes & No \\
\hline & CDI [5] & 0.21 & 0.28 & 0.22 & 0.32 & 0.41 \\
\hline
\end{tabular}

Standard Deviation (SD) of the mean value (by direct method) may be calculated as:

$$
\sigma=\sqrt{\frac{\sum \mathrm{x}^{2}}{\mathrm{~N}}}
$$

Where $\mathrm{x}=$ difference of value of $\mathrm{X}$ from it's mean and $\mathrm{N}$ is number of data points.

\section{Results and discussion}

To deal with multiple regression, we used matrix algebra [6]. Defining $\mathrm{Y}, \mathrm{b}_{\mathrm{i}}$ and $\mathrm{X}_{\mathrm{i}}$ in matrices, we get following: 
$\mathrm{Y}=\left[\begin{array}{c}\mathrm{y} 1 \\ \mathrm{y} 2 \\ . . \\ \mathrm{y}_{\mathrm{n}}\end{array}\right]$ and $\mathrm{b}=\left[\begin{array}{c}\mathrm{b}_{0} \\ \mathrm{~b}_{1} \\ . . \\ \mathrm{b}_{\mathrm{n}}\end{array}\right]$ and $\mathrm{X}=\left[\begin{array}{ccccc}1 & \mathrm{X}_{11} & \mathrm{X}_{12} & . . & \mathrm{X}_{1 \mathrm{n}} \\ 1 & \mathrm{X}_{21} & \mathrm{X}_{22} & . . & \mathrm{X}_{2 \mathrm{n}} \\ . & . . & . . & . . & . . \\ 1 & \mathrm{X}_{\mathrm{n} 1} & \mathrm{X}_{\mathrm{n} 2} & . . & \mathrm{X}_{\mathrm{nn}}\end{array}\right]$

With these matrices, multiple regression equation can be expressed as:

$$
\mathrm{Y}=\mathrm{X} \times \mathrm{b}
$$

Solving this for $\mathrm{b}$, we will get

$$
\mathrm{b}=\left(\mathrm{X}^{\mathrm{T}} \times \mathrm{X}\right)^{-1} \times \mathrm{X}^{\mathrm{T}} \times \mathrm{Y}
$$

Where $\mathrm{X}^{\mathrm{T}}$ is transpose matrix of $\mathrm{X}$.

So matrices for Village 1 from Tab. 3 is as follow:

$\mathrm{Y}=\left[\begin{array}{c}0 . \\ 0.18 \\ 0.21\end{array}\right]$ and $\mathrm{X}=\left[\begin{array}{cccc}1 & 215.03 & 148.225 & 169.042 \\ 1 & 165 & 200 & 220 \\ 1 & 36.4 & 52 & 57\end{array}\right]$

For Village 2 from Tab. 3:

$\mathrm{Y}=\left[\begin{array}{l}0.54 \\ 0.37 \\ 0.28\end{array}\right]$ and $\mathrm{X}=\left[\begin{array}{cccc}1 & 74.1 & 155.967 & 127.117 \\ 1 & 250 & 250 & 300 \\ 1 & 6.56 & 14.66 & 26.23\end{array}\right]$

For Village 3 from Tab. 3:

$\mathrm{Y}=\left[\begin{array}{l}0.53 \\ 0.22 \\ 0.22\end{array}\right]$ and $\mathrm{X}=\left[\begin{array}{cccc}1 & 92.88 & 188.71 & 114.6 \\ 1 & 275 & 275 & 275 \\ 1 & 16.39 & 21.11 & 59.84\end{array}\right]$

For Village 4 from Tab. 3:

$\mathrm{Y}=\left[\begin{array}{l}0.35 \\ 0.31 \\ 0.32\end{array}\right]$ and $\mathrm{X}=\left[\begin{array}{cccc}1 & 147.17 & 257.12 & 174.87 \\ 1 & 150 & 150 & 220 \\ 1 & 23.23 & 27.92 & 36.6\end{array}\right]$

For Village 5 from Tab. 3:

$\mathrm{Y}=\left[\begin{array}{c}0 . \\ 1 . \\ 0.41\end{array}\right]$ and $\mathrm{X}=\left[\begin{array}{cccc}1 & 139.2 & 181.75 & 193.86 \\ 1 & 100 & 150 & 180 \\ 1 & 0 & 8.72 & 17.15\end{array}\right]$

Coefficients of regression from these matrices are listed in Tab. 4.

Table 4: Regression coefficients

\begin{tabular}{c|c|c|c|c}
\hline & $\mathrm{b} 0$ & $\mathrm{~b} 1$ & $\mathrm{~b} 2$ & $\mathrm{~b} 3$ \\
\hline Village 1 & 0.202584 & -0.0020846 & -0.000484543 & 0.0021048 \\
\hline Village 2 & 0.262071 & -0.00236748 & 0.00287471 & 0.000215721 \\
\hline Village 3 & 0.445411 & 0.00140452 & 0.00287783 & -0.00279841 \\
\hline Village 4 & 0.327747 & 0.000774569 & -0.000133504 & -0.00222315 \\
\hline Village 5 & -0.0700598 & -0.0979821 & 0.0901313 & -0.0165505 \\
\hline
\end{tabular}

In Tab. 5 we have calculated descriptive statistics for regression coefficients. As evident from Tab. 5, one can observe that, b1 factor which represents fertilizers, affects most among all independent variables. Irrigation in tribal farming affects least. This agrees with our earlier understanding that, most of tribal farming land are rain-feed only [5].

To visualize multiple linear regression, we have varied independent parameters in a reasonable limit and using regression coefficients from Tab. 4 we got regression equations. From these MLR equations, we calculated dependent variable, CDI. The results are presented in Fig. 1 for all the five villages. 
Table 5: Descriptive Statistics

\begin{tabular}{c|c|c|c|c} 
Regression coefficient & $\mathrm{b} 0$ & $\mathrm{~b} 1$ & $\mathrm{~b} 2$ & $\mathrm{~b} 3$ \\
\hline Mean & 0.233551 & -0.020051 & 0.0190532 & -0.00385031 \\
\hline SD & 0.171878 & 0.0389944 & 0.0355678 & 0.00658855
\end{tabular}

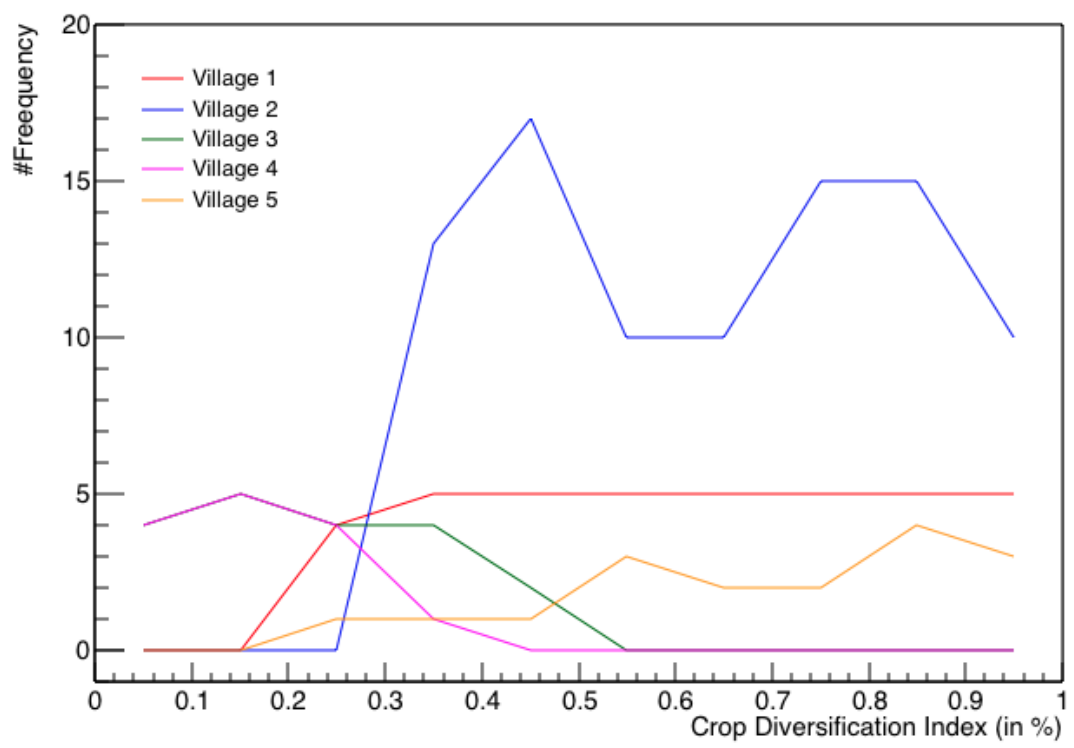

Figure 1: (Color online) CDI for different villages, calculated from Multiple linear regression equation for all five villages

The figure shows combine impact of the changing variables of 3 different time periods on the crop diversification. Here we have fluctuated the maximum and minimum possible variations in Independent variables (rain, fertilizer and irrigated area) and its impact on the extent of crop diversification. In village 1 the impact of rainfall and fertilizer is not there but the irrigation facility is responsible for crop diversification but in case of village 2 the use of fertilizer has a proportionate impact on the growth of crop diversification. In case of village 3 and 4 there is no such instances of crop diversification. In case of village 5 there is a positive impact of the growth of crop diversification. Here we can see the use of fertilizers has a remarkable impact on the crop diversification.

One can see the similar kind of agricultural practice in between Village 1 and Village 3, where, there is a greater effect of modernization but in a case of Village 2 and Village 4, there applying of the modern techniques is a recent phenomenon. The least effect of the modern techniques and advanced machinery can be experienced in Village 5.

\section{Conclusion and policy recommendations}

In this study we analyzed various factors affecting crop diversification in our study area. The study area is tribal dominated region of eastern-ghats of India, Koraput. Over a gap of 5years each, we choose 3 different time periods to observe the factors affecting crop diversification. For a combined impact analysis, we used regression formalism. We observe that Irrigation has the least impact on the extent of crop diversification but the use of fertilizer has a good impact on the growth of crop diversification in these tribal dominated regions.

From the field study it was found there is a need of training to the farmers, may be demonstrated at village level by the concern officials so that they can apply the techniques in a better 
way. Training can be provided for right proportion of the quantity of fertilizer to apply in the land and it's use in a suitable time is the need of the day.

Apart from this, markets can be established for the easy transportation for the farmers to sell their product nearby their villages. Lack of availability of the farmers and distant traveling reduce their will power for crop diversification.

As a policy suggestion, we think government should make schemes to strengthen the economics infrastructure which would support the pace of agricultural growth in the study ares. For example, facilitating cold store houses in which they can store their vegetables at least for 3-4 days and which will not affect them adversely during the period of harvesting and selling. Apart from this, policies should be framed to support the MSP (minimum support price) for the agricultural outputs especially the diversified crops to induce the farmers for drop diversification. The central government is planning to double the farmers income by raising the price of the agricultural products by 2022 which would make a difference to bridge the gap in between inequalities and equalities with special reference to Indian farmers [11].

And finally regional centers should be developed to test the quality of soil and to suggest the farmers about the type of crop they can produce in that soil. Exclusive training centers should be developed at block level to facilitate the cultivation knowledge to the farmers at rural areas.

\section{References}

[1] Census of India 2011; INSTRUCTION MANUAL FOR HOUSELISTING AND HOUSING CENSUS

[2] http://agricoop.nic.in/sites/default/files/Annual_rpt_201617_E.pdf

[3] ftp://ftp.ecn.purdue.edu/vmerwade/class/GDT/Reports_ Books/assessmentofirrigationinIndia.pdf

[4] http://mezeylab.cb.bscb.cornell.edu/labmembers/documents/supplement5multipleregression.pdf

[5] Sadasiba Tripathy, Dr. Sandhyarani Das, "Impact of crop diversification on tribal farmer's income: A case study from Eastern ghats of India", arXiv:2010.10208 [econ.GN]

[6] https://stattrek.com/multiple-regression/regression-coefficients.aspx

[7] https://rainfall.nic.in/PubRainChart.asp

[8] Patil, G.P. and Taillie, C. (1982): Diversity as a concept and its measurement. Journal of American Statistical Association, 77, 548-568.

[9] Diversification of agriculture in tribal tracks of KBK region of Odisha by Sadasiba Tripathy; SLAA publications, Bangalore, March 2019, Vol 6, Issue 3, Pages 57-62 http: //ijmsrr.com/downloads/2004201910.pdf

[10] https://en.wikipedia.org/wiki/M._S._Swaminathan

[11] NITI policy paper No 1/2017; "Doubling farmer's income, Rationale, Strategy, Prospects and Action Plan. https://niti.gov.in/writereaddata/files/document_ publication/DOUBLINGFARMERSINCOME.pdf

[12] Tripathy, Sadasiba (2020), "factors affecting crop diversification, koraput 2008-2018", Mendeley Data, V1, doi: 10.17632/dpvkpnj2n8.1 